\title{
Perioperative management of a patient with primary hypoparathyroidism and severe hypocalcaemia for lumbar spine surgery
}

\author{
Deepak Madankar, Sheetal Samel, Abhay Ganar, Neelesh Mathankar
}

\begin{abstract}
Primary hypoparathyroidism and consequent hypocalcaemia in the absence of iatrogenic cause are a rare entity. Serum ionised calcium concentrations $<0.50 \mathrm{mmol} \mathrm{I}^{-1}$ are more frequently associated with life-threatening complications and constitute a medical emergency that necessitates intravenous calcium therapy. The anaesthesiologist should carefully look for the effects of hypocalcaemia on the heart, circulation, muscle power and blood coagulation. We report perioperative management of a case of hypoparathyroidism and associated hypocalcaemia posted for lumbar discectomy in prone position and its anaesthetic implications.
\end{abstract}

Key words: Anaesthesia, hypocalcaemia, life-threatening complications, primary hypoparathyroidism, spine surgery

\section{INTRODUCTION}

Primary hypoparathyroidism is the absence or destruction of parathyroid tissue that causes a deficiency in parathyroid hormone (PTH) with consequent decreased blood levels of calcium (hypocalcaemia) and increased levels of blood phosphorus (hyperphosphatemia). The symptoms of hypoparathyroidism are synonymous with hypocalcaemia and can range from quite mild (tingling in the hands, fingers, and around the mouth) to more severe forms of muscle cramps leading all the way to tetany and convulsions. ${ }^{[1,2]}$

Calcium has several main functions in human body including: (1) Providing the electrical energy for nervous system, (2) providing the electrical energy for muscle

Department of Anaesthesiology, Meditrina Institute of Medical Sciences, Nagpur, Maharashtra, India

Address for correspondence:

Dr. Deepak Madankar, Department of Anaesthesiology, Meditrina

Institute of Medical Sciences, Nagpur, Maharashtra, India.

E-mail: deepakm30@yahoo.in

\begin{tabular}{|l|l|}
\hline \multicolumn{2}{|c|}{ Access this article online } \\
\hline Quick Response Code: & Website: \\
\hline & www.jnaccjournal.org \\
\cline { 2 - 2 } & \\
\hline & \\
\end{tabular}

contraction, and (3) providing strength to bones. The symptoms of hypocalcaemia are primarily due to dysfunction of nerves and to a lesser extent muscles. We report perioperative management of a case of hypoparathyroidism and associated hypocalcaemia posted for lumbar discectomy in the prone position.

\section{CASE REPORT}

A 38-year-old male patient weighing $101 \mathrm{~kg}$ presented with L 4/5 lumbar canal stenosis with disc prolapse and neurogenic claudication. He was a diagnosed case of primary hypoparathyroidism (owing to deficient intact PTH levels of $5.9 \mathrm{pg} / \mathrm{ml}[\mathrm{N}-15-65 \mathrm{pg} / \mathrm{ml}])$ presenting at the age of 12 years with the clinical manifestations of generalised seizures and tetany secondary to severe hypocalcaemia and was on long-term oral calcium and Vitamin D supplements.

The patient was suffering from hypertension since last 10 years (medically managed with amlodipine $5 \mathrm{mg}$

This is an open access article distributed under the terms of the Creative Commons Attribution-NonCommercial-ShareAlike 3.0 License, which allows others to remix, tweak, and build upon the work non-commercially, as long as the author is credited and the new creations are licensed under the identical terms.

For reprints contact: reprints@medknow.com

How to cite this article: Madankar D, Samel S, Ganar A, Mathankar N. Perioperative management of a patient with primary hypoparathyroidism and severe hypocalcaemia for lumbar spine surgery. J Neuroanaesthesiol Crit Care 2016;3:49-51. 
and atenolol $25 \mathrm{mg}$ combination) to which losartan potassium $50 \mathrm{mg}$ was added on admission. Neurological examinations revealed no signs of cerebellar or extrapyramidal dysfunction. Both the lower limbs showed severe numbness suggestive of neurogenic claudication. In pre-anaesthesia check-up, systemic examination revealed stable haemodynamics with pulse rate of $78 / \mathrm{min}$ and non-invasive blood pressure (NIBP) of $142 / 88 \mathrm{mmHg}$. There were no signs of congestive cardiac failure. Previous surgical/anaesthetic history was negative for any thyroid, parathyroid or any other head and neck surgery except uneventful surgery for hydrocele and bilateral cataract in last 15 years. There was no significant contributory family history.

The laboratory data showed mild anaemia with haemoglobin of $11.2 \mathrm{~g} / \mathrm{dl}$, severe hypocalcaemia serum ionic calcium $0.56 \mathrm{mmol} / \mathrm{L}$, hyperphosphatemia $6.0 \mathrm{mg} / \mathrm{dl}$ (2.3-4.7 mg/dl), normal magnesium $1.53 \mathrm{mEq} / \mathrm{L}$ (1.3-2.5), $\mathrm{Na} 143 \mathrm{mEq} / \mathrm{L}, \mathrm{K} 3.9 \mathrm{mEq} / \mathrm{L}$ and alkaline phosphatase 237.9. The total protein $7.0 \mathrm{~g} / \mathrm{dl}$, albumin 4.2 , globulin 2.8 and $\mathrm{A} / \mathrm{G}$ ratio 1.5. Blood urea nitrogen $40.4 \mathrm{mg} / \mathrm{dl}$ and creatinine $1.29 \mathrm{mg} / \mathrm{dl}$ were also unremarkable.

Pre-operatively, a day prior to scheduled operative procedure, the patient was started with calcium gluconate infusion of $90 \mathrm{mg} / \mathrm{h}(\sim 1 \mathrm{mg} / \mathrm{kg} / \mathrm{h})$ for $10 \mathrm{~h}$. The serum ionic calcium value repeated in the morning of surgery was 0.88 . We decided to continue calcium gluconate infusion of $54 \mathrm{mg} / \mathrm{h}(\sim 0.5 \mathrm{mg} / \mathrm{kg} / \mathrm{h})$ in the intraoperative period as well. Morning dose of losartan potassium was omitted and single dose of tab. Chlorothiazide $25 \mathrm{mg}$ was given orally with sips of water. Immediate pre-operative electrocardiogram (ECG) was unremarkable with QTC of 0.42 . The other biochemical profile was within normal limits and vitals were stable.

In the operative room, all standard monitors (ECG, NIBP, pulse oximetry) were applied. Right upper limb radial artery cannulation was done with $20 \mathrm{G}$ arterial cannula after local skin infiltration. Pre-medication was given with $2 \mathrm{mg}$ midazolam, $1 \mathrm{mcg} / \mathrm{kg}$ fentanyl and $8 \mathrm{mg}$ ondansetron. Induction of anaesthesia was done with $120 \mathrm{mg}$ of propofol and after confirmation of easy mask ventilation muscle relaxation was provided with atracurium $40 \mathrm{mg}$. The trachea was intubated in first attempt with flexometallic (armoured) endotracheal tube no 8.5 with the help of a bougie; glottis visualisation being Cormack-Lehane grade 3 .

Anaesthesia was maintained with oxygen-nitroussevoflurane-atracurium combination titrated to maintain 1 minimum alveolar concentration and adequate muscle relaxation. The surgery lasted $2 \mathrm{~h}$ and rest of the intraoperative period remained uneventful. Total atracurium used was $70 \mathrm{mg}$ that was reversed satisfactorily at the end of the procedure by $4.0 \mathrm{mg}$ of neostigmine and $0.8 \mathrm{mg}$ of glycopyrrolate. Arterial blood gas (ABG) and electrolytes done intraoperatively showed mild respiratory acidosis $\left(\mathrm{PCO}_{2}-48\right)$ and ionic calcium of 0.93. Other ABG parameters, sodium, potassium, magnesium were within normal limits.

Assessment of reversal from neuromuscular blockers was done clinically (sustained head lift for more than $5 \mathrm{~s})$. Once the patient regained complete sensorium and adequate muscle power, trachea was extubated. The patient was shifted to intensive care unit for post-operative management. Calcium gluconate infusion of $0.5 \mathrm{mg} / \mathrm{kg} / \mathrm{h}$ was continued into the post-operative period for $6 \mathrm{~h}$. The patient was allowed oral feed at the end of $4 \mathrm{~h}$ post-extubation and received regular oral calcium dose (1000mg Calcium/day).

Ionic calcium values at the end of 12,24 and $36 \mathrm{~h}$ post-operative period were $0.90,0.92$ and $0.88 \mathrm{mmol} / \mathrm{L}$ respectively. The patient was discharged uneventfully on third post-operative day on oral calcium and antihypertensive drugs. He was advised regular follow-up with endocrinologist, neurosurgeon and anaesthesiologist for any post-operative concerns.

\section{DISCUSSION}

Primary hypoparathyroidism and consequent hypocalcaemia in the absence of iatrogenic cause presenting for surgical procedure is a rare entity as found in our case. The most common cause of hypoparathyroidism is loss of parathyroid tissue following thyroid or parathyroid surgery ${ }^{[3]}$ Varied clinical findings accompanied by hypoparathyroidism and hypocalcaemia were observed in our case. Low PTH levels result in excessive urinary calcium losses, decreased bone remodelling, and reduced intestinal calcium absorption leading to hypocalcaemia. ${ }^{[2,4]}$ Rarely, PTH resistance in the form of pseudohypoparathyroidism can produce a similar physiologic profile and should be considered in the presence of an elevated serum PTH level. ${ }^{[5]}$ Autoimmune hypoparathyroidism and genetic mutations can also lead to hypoparathyroidism and hypocalcaemia.

Various symptoms of hypocalcaemia that include paraesthesia, muscle spasms, cramps, tetany, circumoral numbness, and seizures ${ }^{[1,4,6]}$ were very well documented in this patient. Other clinical signs of hypocalcaemia are clumsiness; convulsions; laryngeal stridor; depression; muscle stiffness; parkinsonism; Chvostek's sign; dry scaly skin, brittle nails, and coarse hair; prolonged QT intervals; soft tissue calcifications; and Trousseau's sign. ${ }^{[7]}$

It is essential to ask about family history of hypocalcaemia as this can indicate a genetic cause for the hypoparathyroidism. Growth or mental retardation, congenital anomalies, or hearing loss may suggest 
the presence of a genetic abnormality. ${ }^{[6]}$ On physical examination, look for neck scarring, as patients might not recall remote neck surgery. Chvostek and Trousseau signs can be elicited in patients with hypocalcaemia. Chvostek sign is the twitching of the upper lip with tapping on the cheek $2 \mathrm{~cm}$ anterior to the earlobe, below the zygomatic process overlying the facial nerve. ${ }^{[8]}$ Trousseau sign (a more reliable sign present in $94 \%$ of hypocalcaemic individuals and only $1-4 \%$ of healthy people) is the presence of carpopedal spasm observed following application of an inflated BP cuff over systolic pressure for $3 \mathrm{~min}$ in hypocalcaemic patients. ${ }^{[8]}$

Mild degrees of hypocalcaemia with ionised calcium $>0.8 \mathrm{mmol} / \mathrm{L}$ are usually asymptomatic and seldom require treatment. In more severe hypocalcaemia, it is more likely that the patient will experience hypocalcaemia-induced symptoms and therefore replacement therapy is appropriate. Serum ionised calcium concentrations $<0.50 \mathrm{mmol} / \mathrm{L}$ are more frequently associated with life-threatening complications and constitute a medical emergency that necessitates intravenous calcium therapy. Initial therapy in adults consists of correction of any coexisting respiratory or metabolic alkalosis and the administration of a calcium bolus (100-200 mg of elemental calcium over $10 \mathrm{~min}$ ), followed by a maintenance infusion of $1-2 \mathrm{mg} / \mathrm{kg} / \mathrm{h}$ of elemental calcium. The serum calcium level usually returns to normal in $6-12 \mathrm{~h}$ with this regimen. Thereafter, the maintenance rate may need to be decreased to $0.3-0.5 \mathrm{mg} / \mathrm{kg} / \mathrm{h}^{\left[{ }^{[1]}\right.}$

Intraoperative metabolic derangements such as alkalosis resulting from hyperventilation can precipitate hypocalcaemia by causing calcium to bind to albumin, thereby lowering the ionised calcium concentration. ${ }^{[9]}$ We tried to avoid alkalosis by keeping $\mathrm{EtCO}_{2}$ values on higher side of around $40\left(\mathrm{PCO}_{2}-44 \mathrm{mmHg}\right.$ at the end of procedure). Thiazide diuretics may help in hypocalcaemia by decreasing urinary calcium excretion by increasing distal renal tubular calcium reabsorption. ${ }^{[1,6]}$ Magnesium deficiency or alkalosis should be corrected if present. ${ }^{[1,6,10]}$ Acutely, magnesium supplementation therapy will not elevate serum PTH or calcium, as peripheral PTH resistance can last for several days. ${ }^{[11]}$

Calcium plays a central role in synaptic and neuromuscular transmission through changes in transmembrane calcium flux at the neuromuscular junction. The action of muscle relaxants may be prolonged and smaller doses may be required, with further increments administered in response to the results of neuromuscular monitoring which is highly desirable in patients of hypocalcaemia. Hypocalcaemia may present as laryngospasm in the immediate post-operative phase, particularly after neck surgery, and may require re-intubation of the trachea ${ }^{[5]}$ which can be resolved with calcium repletion. ${ }^{[12]}$

\section{CONCLUSION}

The calcium ion has a very important role to play in physiological processes involved during the conduct of anaesthesia. The anaesthesiologist should carefully look for the effects of hypocalcaemia on the heart, circulation, muscle power and blood coagulation. Adequate pre-operative assessment and appropriate treatment, if required, is essential before elective surgery.

If anaesthesia has to be administered when hypocalcaemia exists, particular attention must be paid to the potential additive effects of various anaesthetic agents, in particular the volatile anaesthetics, the action of muscle relaxants may be prolonged and smaller doses may be required and appropriate calcium replacement may attenuate such responses. ${ }^{[5]}$ Finally, perioperative management of patients with hypocalcaemia requires careful understanding of the calcium physiology and metabolism, the ways that it influences our perioperative management, plan for the special needs of this population and lastly careful titration of various drugs and close monitoring of patient is essential.

\section{Financial support and sponsorship} Nil.

\section{Conflicts of interest}

There are no conflicts of interest.

\section{REFERENCES}

1. Murphy E, Williams GR. Hypocalcaemia. Medicine 2009;37:465-8.

2. Khan A, Bilezikian J. Primary hyperparathyroidism: Pathophysiology and impact on bone. CMAJ 2000;163:184-7.

3. Fong J, Khan A. Hypocalcemia: Updates in diagnosis and management for primary care. Can Fam Physician 2012;58:158-62.

4. Cooper MS, Gittoes NJ. Diagnosis and management of hypocalcaemia. BMJ 2008;336:1298-302.

5. Aguilera IM, Vaughan RS. Calcium and the anaesthetist. Anaesthesia 2000;55:779-90.

6. Shoback D. Clinical practice. Hypoparathyroidism. N Engl J Med 2008;359:391-403.

7. Roizen MF, Fleisher LA. Anesthetic implications of concurrent diseases. In: Miller RD, Eriksson LI, Fleisher LA, WienerKronish JP, Young WL, editors. Miller's Anesthesia. $7^{\text {th }}$ ed. Philadelphia: Churchill Livingstone; 2010. p. 1067-150.

8. Urbano FL. Signs of hypocalcemia: Chvostek's and Trousseau's signs. Hosp Physician 2000;36:43-5.

9. Schonberger RB. Fluid electrolyte and acid base disorders. In: Stoelting RK, Hines RL, Marschall KE, editors. Stoelting's Anesthesia and Co-existing Disease. $6^{\text {th }}$ ed. Philadelphia: Elsevier Health Sciences; 2012. p. 357-75.

10. MaedaSS, FortesEM, OliveiraUM, BorbaVC, Lazaretti-CastroM. Hypoparathyroidism and pseudohypoparathyroidism. Arq Bras Endocrinol Metabol 2006;50:664-73.

11. Tohme JF, Bilezikian JP. Diagnosis and treatment of hypocalcemic emergencies. Endocrinologist 1996;6:10-8.

12. Zaloga GP, Chernow B. Hypocalcemia in critical illness. JAMA 1986;256:1924-9. 